\title{
Collective Intelligence in Knowledge Management
}

\author{
Wenyan Yuan', Yu Chen ${ }^{1}$, Rong Wang ${ }^{1,2}$ and Zhongchao Du ${ }^{1}$ \\ 'School of Information, Renmin University of China, Beijing 100872, P.R. China \\ dongtinghu1982@163.com rong@ruc.edu.cn yuchen318@gmail.com duzc@ruc.edu.cn \\ ${ }^{2}$ Key Laboratory of Information Management and Information Economics, Ministry of \\ Education P.R.C, Beijing 100876, P.R. China rong@ruc.edu.cn
}

\begin{abstract}
This paper traces the history of research for Collective Intelligencc, and describes new forms of Collective Intelligence on the Internet so far especially from the view of Web2.0, to figure out what Collective Intelligence is, then makes analyses on those forms to make clear the mechanism of Collective Intelligence on the Internet. As one Complex Adaptive System, Collective Intelligence is the emergence of group behaviors, and is stored on the platform of the Internet. So, it is one new kind of the Knowledge Management on the Intemet. We finally think about future work for this field to promote the emergence of Collective Intelligence on the Internet.
\end{abstract}

Keywords: Collective intelligence, Social software, Weh2.0, Complex adaptive system, Knowledge management, Data mining, Semantic Web

\section{INTRODUCTION}

The words "Collective Intelligence" may first be widely used in ant-based research, which later developed as "Swarm Intelligence" [1, 2]. And many scholars believe that one antecedent for Collective Intelligence is "Global Brain" [3]. Howard Bloom $[4,5]$ stresses the biological adaptations that have turned most of this earth's living beings into components of what he calls "a learning machine". One $\mathrm{Cl}$ pioneer, George Pór, defined the Collective Intelligence phenomenon as "the capacity of a human community to evolve toward higher order complexity thought, problemsolving and integration through collaboration and innovation."'[6]

With new communication technologies-especially the Internet-huge numbers of people all over the planet can now work together in ways that were never before possible in the history of humanity. It is thus more important than ever for us to understand Collective Intelligence at a deep level so we can create and take advantage of these new possibilities.

This paper will have a description for some important styles and technologies related to Collective Intelligence on the Internet, and analyze the mechanism for it on the Internet, finally think about future work for this field.

\footnotetext{
Please use the following format when citing this chapter

Yuan, W.. Chen. Y., Wang, R., Du. /., 2007, in IFIP International Federation for Information Processing. Volume 254. Research and Practical Issues of I.nterprise Information Systens II Volume I, culs. L. Xu. I joa A. Chaudhry S. (Boston: Springer). pp. 651-655
} 


\section{COLLECTIVE INTELLIGENCE ON THE INTERNET}

Collective Intelligence is now occurring in dramatically new forms on the Internet. The popularity of Social Software, and the springing up of workshop of Web 2.0, are all characterized by harnessing Collective Intelligence. To have an analysis for these new forms, we here, will have a description for some important styles and technologies of Collective Intelligence. Before all this, we draw one figure below to facilitate coming illumination.

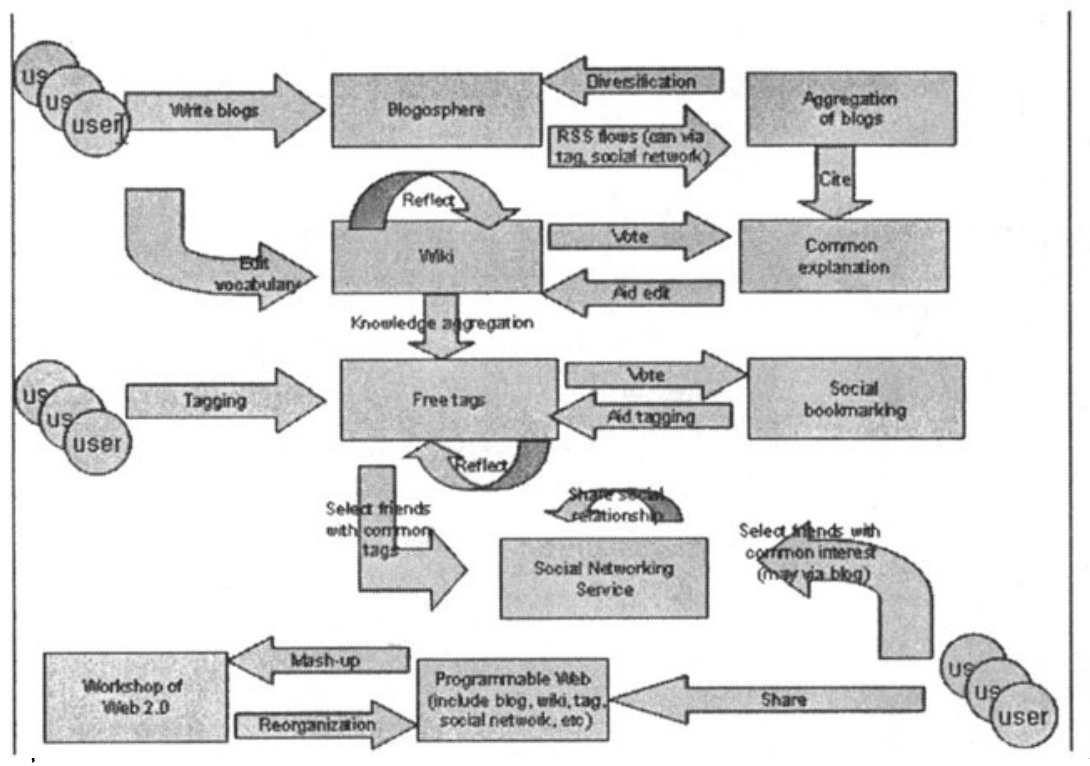

Figure 1. Collective Intelligence Mechanism on the Internet

\subsection{Social Software}

Blog, Social Bookmarks, Social Networking Service, and Wiki, are the four main kinds of Social Software that are known today by thousands of networks people, and are deemed as Classical Social Software.

1) Blogs

The first main difference between web 1.0 and web 2.0 just lay at whether users can write besides traditional read on the web. Although sharing ideas, facts, and opinions in electronic communities was not new, by opening the "means of production" to non-programmers everywhere, blogs introduced that highly combustible fuel-critical mass, and forming blogosphere.

2) Social Bookmarks 
Introduced in 2003, the del.icio.us social bookmark manager was one of the first of its type and has enjoyed an early and large base of committed users ${ }^{1}$. The emergent social bookmarks coming from the collaboration of individual intelligence of free tagging is named by Thomas Vander Wal as Floksonomy (which is the combination of Folks and Taxonomy) [7].

3) Wikis

Wiki pages are editable and changeable by anyone. In the worldwide encyclopedia Wikipedia ${ }^{2}$, the forming of stable explanation for vocabulary (common vocabulary in the figure) is the emergence of Collective behaviors, in which people reflect each other by voting or changing other's explanations.

4) Social Networking Service

First, people may find their friend by selecting people with common interest on the blogs or with common tags. Further, because these systems record the social network, enable the share and transferring of social relationship, so they provide one global social relationship view. Through this global view, strangers can become friends via their friends' friendship, and this promotes the aggregation of users with common interest, and the forming the self-organization in the social network.

\subsection{Technologies to Motivate Collective Intelligence}

The application of RSS (Syndication) and Programmable Web actually do not involve new technologies, but truly make convenience to the environment to activate Collective Intelligence.

1) RSS

To aggregate other RSS files and to be aggregated by other RSS aggregators, the remixing and remixed files which syndicated towards different kinds of taste from users motivate the aggregation of individual intelligence. Information flows are mainly via RSS, which promotes the aggregation of individual intelligence. Via this important process, the Internet becomes really active and diversiform, with each adaptive agent changing every moment according to each other..

2) Share and Mash-ups for Programmable Web

Social Softwares open their APIs to allow other systems to use for further developing. If one system can be used as plug-in for other systems, and even can used entirely as one plug-in for another system, then this system is seen as programmable web. Web 2.0 is feathered as "share, reorganization, mash-ups", and these feathers can produce the systems that are called the workshop of web 2.0, one form of which is the mash-ups of programmable web.

\footnotetext{
Del.icio.us; http://del.icio.us/.

See www.wikipedia.com
} 


\section{COLLECTIVE INTELLIGENCE AND ITS MECHANISM ON THE INTERNET}

We have talked too much, but what is Collective Intelligence, and what's its mechanism on the Internet. We are going to explore this.

\subsection{Definition for Collective Intelligence}

From the Handbook of Collective Intelligence, there is: Collective Intelligence is Groups of individuals doing things collectively that seem intelligent ${ }^{3}$.

That is, Collective Intelligence is the combination of individual intelligence, but as one Complex Adaptive System, it is more than the addition of individual intelligence. As the adaptive agents (individual intelligence) acted individually and mutually, Collective Intelligence gradually emerges.

\subsection{Mechanism on the Internet for Collective Intelligence}

Collective Intelligence has its own characteristics emerging on the Internet. We induced them as seven basic ones: Aggregation, Tagging, and Nonlinearity, and Information flows, Diversity, Selectivity, building blocks

People may find these characteristics are similar with the ones listed for CAS [8], and since we deem Collective Intelligence as CAS, we will be sure to reference it a lot.

The characteristics listed above are implicated in the Fig.1. No mater with blog, wiki, or Social Bookmarking, Social Networking Service, there is aggregations, just with different contents, for example, aggregation of common vocabulary, social relationship, and Floksonomy. Tagging helped aggregation when people select their friends, and selectivity from individuals accomplished this aggregation too. In this picture, the information flows are mainly via RSS, and this makes the Internet active, diversiform, and changing, so that new intelligence emerges.

Each system, with the reflection mechanism embedded, is not linear any more. So they are nonlinear. This nonlinearity makes Collective Intelligence complex and emergent. And with Programmable Web, the Internet is divided into one and one building blocks, which by mixing, facilitate the building more new and complex systems. The Internet is becoming vivid.

Each individual, as one adaptive agent, contributes knowledge, communicates with another, refer to another, votes for others, and modifies other's knowledge, and accomplish the emergence of Mass Intelligence. As one CAS, Collective Intelligence is the emergence of group behaviors, but is stored on the platform of the Internet. So, from this view, we can also say that, Collective Intelligence is also the Knowledge Management on the Internet.

${ }^{3}$ This definition is from "the Handbook of Collective Intelligence" from the MIT Centre for Collective Intelligence, see http://www.socialtext.net/mit-cci-hci/index.cgi?handbook_of_collective_intelligence. 


\section{CONCLUSIONS}

We are going to interpret mechanism of Collective Intelligence on the Internet more detailed in the future. The research of this field to promote the emergence of Collective Intelligence needs the help from the field of Date Mining and Semantic Web.

Scholars summarized that there are three main components of Web 2.0: social software, the semantic web and information retrieval. Right now, the idea for semantic web and information retrieval being characteristic by harnessing Collective Intelligence is coming out, and in our opinion, will later become flourishing just like Social Software. We are eager to see that and will continue to keep an eye on the development of Collective Intelligence on the Internet.

\section{ACKNOWLEDGEMENTS}

This work is supported by National Social Science Foundation Grant \#06BTQ016 and Open Foundation of Key Laboratory of Information Management and Information Economics, Ministry of Education P.R.C, Grant \#F0607-16.

\section{REFERENCES}

1. E. Bonabeau, M. Dorigo, and G. Theraulaz, Swarm Intelligence: From Natural to Artificial Systems, Santa Fe Institute Studies in the Sciences of Complexity (Oxford University Press: New York, 1999).

2. J. Kennedy and R. C. Eberhart, Swarm Intelligence (Morgan Kaufmann Publishers: San Francisco, 2001).

3. B. Goertzel, Creating Internet Intelligence, Wild Computing, Distributed Digital Consciousness, and the Emerging Global Brain (Plenum Press: New York, 2001).

4. H. Bloom, Global Brain, The Evolution of Mass Mind from the Big Bang to the 2Ist Century (Wiley: New York, 2000).

5. H. Bloom, The Lucifer Principle: A Scientific Expedition into the Forces of History (Atlantic Monthly Press: New York, 1995).

6. G. Pór, Blog of Collective Intelligence (May 10, 2006). http://www.communityintelligence.com/blogs/public/(Accessed March 4, 2007).

7. T. Vander Wal, Folkonomy. http://www.vanderwal.net/essays/051130/folksonomy.pdf (Accessed March 4, 2007).

8. J.H. Holland, Hidden order: how adaptation builds complexity (Addison-Wesley: Massachusetts, 1995). 